\title{
A Two-Stage Quantity-Setting Duopoly: Cournot or Stackelberg
}

\author{
Kazuhiro Ohnishi
}

Institute for Basic Economic Science, Japan

\begin{abstract}
This paper considers a two-stage quantity-setting duopoly model. In the first stage, each firm independently announces its output. Each firm can discount its announced output but cannot raise it. In the second stage, each firm independently chooses its actual output. The paper classifies demand functions into the following four cases in terms of the goods relevance and strategic relevance between both firms: "substitute goods and strategic substitutes", "substitute goods and strategic complements", "complementary goods and strategic substitutes" and "complementary goods and strategic complements". The paper presents the subgame perfect Nash equilibrium in each of four cases.
\end{abstract}

Keywords Two-Stage Model, Cournot Equilibrium, Stackelberg Equilibrium

\section{Introduction}

The analysis of [3] considers a two-stage price-setting duopoly model. ${ }^{1}$ The two stages are as follows. In the first stage, each firm simultaneously and independently announces its price. The firms cannot raise their announced prices, but can discount them. At the end of the first stage, each firm knows its rival firm's price. In the second stage, each firm simultaneously and independently chooses its actual price. At the end of the second stage, the market opens. He classifies demand functions into the following four cases in terms of the goods relevance and strategic relevance between both firms: "substitute goods and strategic complements", "substitute goods and strategic substitutes", "complementary goods and strategic complements" and "complementary goods and strategic substitutes". He demonstrates that the subgame perfect Nash equilibrium outcomes depend on the properties of each firm's demand function, and therefore, there are three patterns of equilibrium outcomes: Bertrand equilibrium only, Stackelberg equilibrium only, and both equilibria.

We examine a two-stage quantity-setting duopoly model. We also classify demand functions into four cases in terms of the goods relevance and strategic relevance between both firms: "substitute goods and strategic substitutes", "substitute goods and strategic complements", "complementary

* Corresponding author:

ohnishi@e.people.or.jp (Kazuhiro Ohnishi)

Published online at http://journal.sapub.org/economics

Copyright (C) 2012 Scientific \& Academic Publishing. All Rights Reserved goods and strategic substitutes", and "complementary goods

${ }^{1}$ See Gilbert [2], Shapiro [6] and Tirole [7] for excellent surveys of oligopoly models. and strategic complements". We present the subgame perfect Nash equilibrium in each of four cases by using the twostage quantity-setting model.

The remainder of this paper is organized as follows. In Section 2, we describe the model. Section 3 gives supplementary explanations of the model. Section 4 discusses the equilibrium of the model. Section 5 concludes the paper.

\section{The Model}

In this section, we describe a two-stage quantity-setting game. There are two firms: firm 1 and firm 2. In the remainder of this paper, subscripts 1 and 2 denote firm 1 and firm 2, respectively. In addition, when $i$ and $j$ are used, they should be understood to refer to 1 and 2 with $i \neq j$. There is no possibility of entry or exit. The two stages of the game are as follows. In the first stage, each firm $i$ simultaneously and independently announces its output $x_{i}(1) \in[0, \infty)$. At the end of the first stage, each firm knows $x_{1}(1)$ and $x_{2}(1)$. In the second stage, each firm $i$ simultaneously and independently chooses its actual output $x_{i} \in\left[0, x_{i}(1)\right]$. At the end of the second stage, the market opens and each firm sells its actual output $x_{i}$.

Firm $i$ 's profit is

$$
\pi_{i}\left(x_{i}, x_{j}\right)=p_{i}\left(x_{i}, x_{j}\right) x_{i},
$$

where $p_{i}: \mathfrak{R}_{+}^{2} \rightarrow \mathfrak{R}_{+}$denotes firm $i$ 's inverse demand function.

In this model, we make the following assumption.

Assumption 1. $p_{i}$ is twice continuously differentiable with $\partial p_{i} / \partial x_{i}<0$ (downward-sloping demand).

This assumption ensures a smooth demand function. Throughout the paper, we use subgame perfection as our 
equilibrium concept and restrict our attention to pure strategy equilibria.

\section{Supplementary Explanations}

First, we describe the Cournot equilibrium in quantities. Definition 1. Firm $i$ 's reaction function is defined by $R_{i}\left(x_{j}\right) \equiv \arg \max _{\left\{x_{i} \geq 0\right\}} p_{i}\left(x_{i}, x_{j}\right) x_{i}$.

Definition 2. The Cournot equilibrium is defined as a pair $\left(C_{1}, C_{2}\right)$ of output levels, where $C_{1} \in R_{1}\left(C_{2}\right)$ and $C_{2} \in R_{2}\left(C_{1}\right)$.

The outputs $\left(C_{i}, C_{j}\right)$ of the Cournot equilibrium satisfy the following conditions: The first-order conditions for profit maximization is

$$
p_{i}+\frac{\partial p_{i}}{\partial x_{i}} x_{i}=0,
$$

and the second-order condition for profit maximization is

$$
2 \frac{\partial p_{i}}{\partial x_{i}}+\frac{\partial^{2} p_{i}}{\partial x_{i}^{2}} x_{i}<0
$$

Furthermore, we have

$$
R_{i}^{\prime}\left(x_{j}\right)=-\frac{\partial p_{i} / \partial x_{j}+\left(\partial^{2} p_{i} / \partial x_{i} \partial x_{j}\right) x_{i}}{2\left(\partial p_{i} / \partial x_{i}\right)+\left(\partial^{2} p_{i} / \partial x_{i}^{2}\right) x_{i}}
$$

From (4), we have $\operatorname{sign}\left(R_{i}{ }^{\prime}\right)=\operatorname{sign}\left[\partial p_{i} / \partial x_{j}+\left(\partial^{2} p_{i} / \partial x_{i} \partial x_{j}\right) x_{i}\right]$. Therefore, if $\partial R_{i} / \partial x_{j}$ is negative (respectively positive), firm $i$ 's reaction curve is downward-sloping (respectively upward-sloping) and strategies are strategic substitutes (respectively complements). ${ }^{2}$ We make the following assumption.

Assumption 2. If $\left(R_{i}\left(x_{j}\right), x_{j}\right) \in \Re_{++}^{2}$, then $0 \leq\left|R_{i}{ }^{\prime}\left(x_{j}\right)\right|<1$ (stability condition).

Assumption 2 is a stability condition and guarantees the uniqueness of the Cournot equilibrium for the standard adjustment mechanism. That is,

$$
R_{i}\left(R_{j}\left(x_{i}\right)\right) \begin{cases}>x_{i} & \text { if } x_{i}<C_{i}, \\ =x_{i} & \text { if } x_{i}=C_{i}, \\ <x_{i} & \text { if } x_{i}>C_{i} .\end{cases}
$$

Second, we describe the Stackelberg equilibrium in quantities. Firm $i$ chooses $x_{i}$ and firm $j$ chooses $x_{j}$ after observing $x_{i}$. Given $x_{j}$, firm $i$ maximizes its profit $\pi_{i}\left(x_{i}, R_{j}\left(x_{i}\right)\right)$ with respect to $x_{i}$. The first-order condition for profit maximization is

$$
p_{i}+\left(\frac{\partial p_{i}}{\partial x_{i}}+\frac{\partial p_{i}}{\partial x_{i}} R_{j}^{\prime}\right) x_{i}=0
$$

Definition 3. The Stackelberg leader's profit is defined by $\pi_{i}^{L}\left(x_{i}\right) \equiv \pi_{i}\left(x_{i}, R_{j}\left(x_{i}\right)\right)$

Assumption 3. $\pi_{i}^{L}\left(x_{i}, R_{j}\left(x_{i}\right)\right)$ is strictly concave (Concavity of Stackelberg leader's profit).

\footnotetext{
2 The concepts of strategic substitutes and complements were introduced by Bulow, Geanakoplos, and Klemperer [1].
}

Definition 4. The Stackelberg equilibrium is defined by $L_{i} \equiv \arg \max _{\left\{x_{i} \geq 0\right\}} \pi_{i}^{L}\left(x_{i}\right)$ and $F_{j} \equiv R_{j}\left(L_{i}\right)$, where $L_{i}$ is the Stackelberg leader's output and $F_{j}$ is the Stackelberg follower's output.

\section{Equilibrium Outcomes}

In this section, we discuss the equilibrium outcomes of the two-stage quantity-setting model formulated in Section 2. We consider the following four cases. ${ }^{3}$

Case 1: $\partial p_{i} / \partial x_{j}<0$ and $\partial R_{i} / \partial x_{j}<0$.

Case 2: $\partial p_{i} / \partial x_{j}<0$ and $\partial R_{i} / \partial x_{j}>0$.

Case 3: $\partial p_{i} / \partial x_{j}>0$ and $\partial R_{i} / \partial x_{j}<0$.

Case 4: $\partial p_{i} / \partial x_{j}>0$ and $\partial R_{i} / \partial x_{j}>0$.

Case 1 is the case considered by standard Cournot competition. We now discuss these cases.

\section{Cases 1 and 4}

Case 1 is the case of strategic substitutes in which goods are substitutes. Case 4 is the case of strategic complements in which goods are complements. The equilibrium outcome of these two cases is stated by the following proposition,

Proposition 1. Suppose that Assumptions 1-3 are satisfied. If $\operatorname{sign}\left(\partial p_{i} / \partial x_{j}\right)=\operatorname{sign}\left(\partial R_{i} / \partial x_{j}\right)$, then the set of equilibrium outcomes $E$ is $\left\{\left(C_{1}, C_{2}\right)\right\}$.

The intuition behind Proposition 1 is as follows. First, we illustrate Case 1, which is drawn in Figure 1. $R_{i}$ is firm $i$ 's reaction curve, and $\pi_{i}$ is firm $i$ 's isoprofit contour. In Case 1 , firm $i$ 's reaction curves are downward-sloping because of strategic substitutes. Firm $i$ 's profit increases (respectively decreases) with the fall (respectively rise) of firm $j$ 's output on firm $i$ 's reaction curve. In Figure 1, the Stackelberg point $L_{1}$ where firm 1 is the leader and firm 2 is the follower is to the right of $C$ on the curve $R_{2}$. That is, each firm's Stackelberg leader output exceeds its Cournot output. Firm 1 's profit is the highest at $L_{1}$ on $R_{2}$. The further the point on $R_{2}$ gets from the Stackelberg point $L_{1}$, the more firm 1 's profit decreases. Therefore, firm 1 wants to commit itself to a larger output in the first stage. However, since firm 1 can discount its stated output $x_{1}(1)$, this commitment is not credible. Since the game is symmetric, firm 2's incentives are the same, and hence the equilibrium is at point $C$ in Figure 1.

Next, we illustrate Case 4, which is drawn in Figure 2. In Case 4, firm $i$ 's reaction curves are upward-sloping because of strategic complements. Firm i's profit increases (respectively decreases) with the rise (respectively fall) of firm $j$ 's output on firm $i$ 's reaction curve. The Stackelberg point $L_{1}$ where firm 1 is the leader and firm 2 is the follower is to the right of $C$ on $R_{2}$. Firm 1's profit is the highest at $L_{1}$ on $R_{2}$. Therefore, firm 1 wants to commit itself to a larger output in the first stage. However, since firm 1 can discount

\footnotetext{
${ }^{3}$ For price competition, see Matsumura [3] and Ohnishi [4]. See also Ohnishi [5]. 
its stated output $x_{1}(1)$, this commitment is not credible. Since the game is symmetric, firm 2's incentives are the same. As a result, the equilibrium occurs at $C$ in Figure 2.

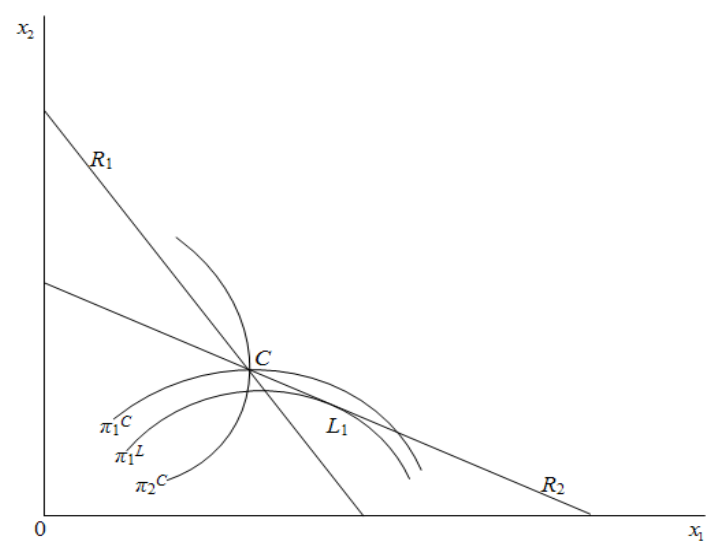

Figure 1. Case 1: Substitute goods and strategic substitutes

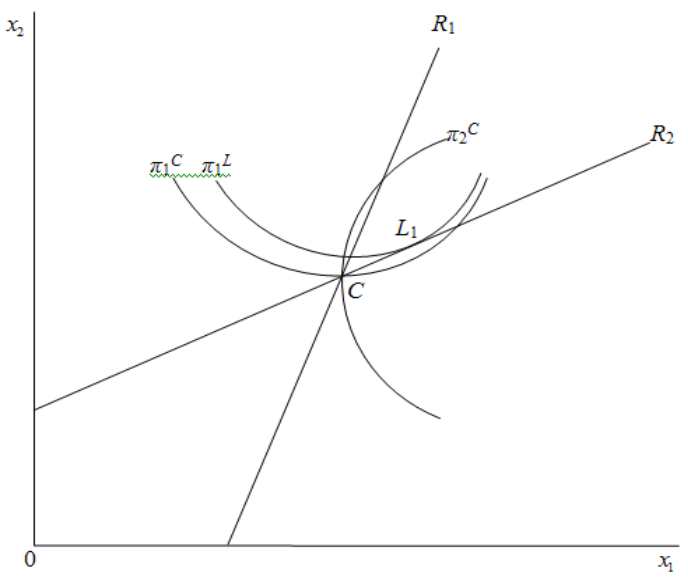

Figure 2. Case 4: Complementary goods and strategic complements

\section{Case 2}

Case 2 is the case of strategic complements in which goods are substitutes. The equilibrium outcome of this case is stated by the following proposition.

Proposition 2. Suppose that Assumptions 1-3 are satisfied. If $\partial p_{i} / \partial x_{j}<0$ and $\partial R_{i} / \partial x_{j}>0$, then $E=\left(L_{1}, F_{2}\right) \cup$ $\left(F_{1}, L_{2}\right)$.

The intuition behind Proposition 2 is straightforward. Case 2 is illustrated in Figure 3. In Case 2, firm $i$ 's reaction curves are upward-sloping because of strategic complements. Firm $i$ 's profit increases (respectively decreases) with the fall (respectively rise) of firm $j$ 's output on firm $i$ 's reaction curve. In Figure 3, the Stackelberg point $L_{1}$ where firm 1 is the leader and firm 2 is the follower is to the left of $C$ on $R_{2}$. That is, each firm's Stackelberg leader output is smaller than its Cournot output. Firm 1's profit is the highest at $L_{1}$ on $R_{2}$. Decreasing firm $i$ 's output decreases firm $j$ 's output because of strategic complements and furthermore increases each firm's profit because of complementary goods and strategic complements. Firm 1 has an incentive to cut firm 2's output and wants to commit itself to a smaller output in the first stage. Since firm 1 can discount its announced output but cannot raise it, this commitment is credible. In our model, firm 1 is able to commit itself to a smaller output. Since the game is symmetric, firm 2's incentives are the same, and hence the equilibrium is $\left(L_{i}, F_{j}\right)$.

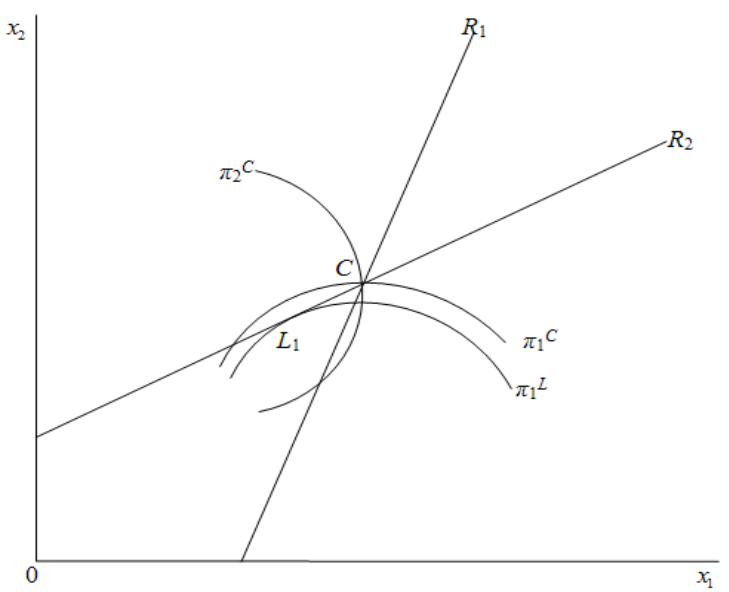

Figure 3. Case 2: Substitute goods and strategic complements

\section{Case 3}

Case 3 is the case of strategic substitutes in which goods are complements. We present the following proposition.

Proposition 3. Suppose that Assumptions 1-3 are satisfied. If $\partial p_{i} / \partial x_{j}>0$ and $\partial R_{i} / \partial x_{j}<0$, then $E=$ $\left\{\left(x_{1}, R_{2}\left(x_{1}\right)\right)\left|x_{1} \in\left[L_{1}, C_{1}\right] \cup\left\{R_{1}\left(x_{2}\right), x_{2}\right)\right| x_{2} \in\left[L_{2}, C_{2}\right]\right\}$.

The intuition behind Proposition 3 is illustrated in Figure 4. In Case 3, firm $i$ 's reaction curves are downward-sloping because of strategic substitutes. Firm $i$ 's profit increases (respectively decreases) with the rise (respectively fall) of firm $j$ 's output on firm $i$ 's reaction curve. The Stackelberg point $L_{1}$ where firm 1 is the leader and firm 2 is the follower is to the left of $\mathrm{C}$ on $\mathrm{R}_{2}$. Firm 1's profit is the highest at $L_{1}$ on $R_{2}$. Decreasing firm $i$ 's output increases firm $j$ 's output because of strategic substitutes and furthermore increases firm 1's profit because of complementary goods and strategic substitutes. Firm 1 wants to commit itself to a smaller output in the first stage. Since firm 1 can discount its announced output but cannot raise it, this commitment is credible. Firm 1 is able to commit itself to a smaller output, and hence the Stackelberg outcome appears.

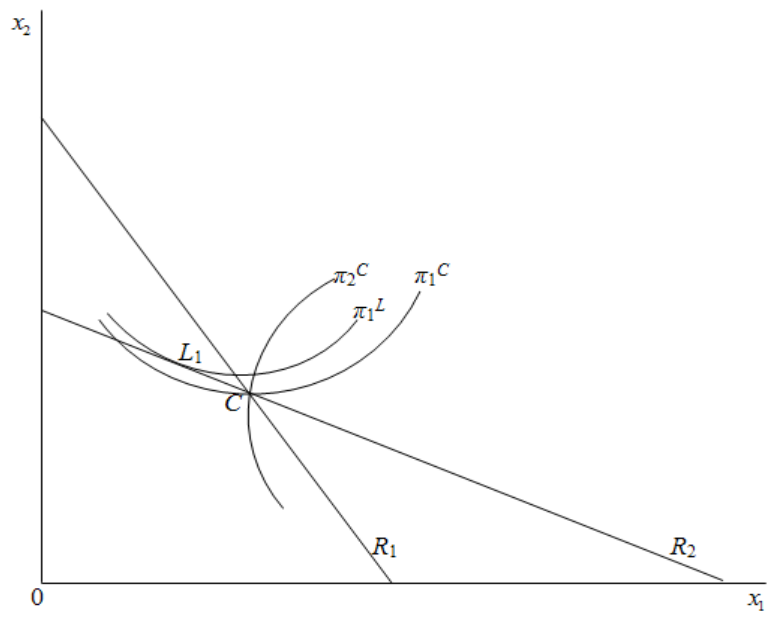

Figure 4. Case 3: Complementary goods and strategic substitutes 
The Cournot equilibrium outcome is also one of the equilibrium outcomes. Suppose that firm $j$ chooses $x_{j}(1)=C_{j}$. Then firm $i$ cannot induce a smaller output than $C_{j}$ from firm $j$, and therefore firm $i$ loses the incentive to announce a smaller output like $L_{i}$. Hence the Cournot outcome appears in equilibrium.

The proofs of Propositions 1-3 are the same as those of Propositions 1-3 in [3] and will be omitted.

\section{Conclusions}

We have classified the demand functions into the four cases in terms of the goods relevance and strategic relevance between two firms and have examined the equilibrium outcome in each of four cases by using a two-stage quantity-setting model. We have shown that the equilibrium outcomes depend crucially on the properties of the demand functions and there are three patterns of equilibrium outcomes: Cournot equilibrium only, Stackelberg equilibrium only, and both equilibria. We have found that our results are the same as those of two-stage price-setting duopoly competition.

\section{REFERENCES}

[1] Bulow, J., Geanakoplos, J., Klemperer, P., 1985. Multimarket oligopoly: strategic substitutes and complements. Journal of Political Economy 93, 488-511

[2] Gilbert, R. J., 1989. Mobility barriers and the value of incumbency. In: Schmalensee, R., Willig, R. D. (Eds.), Handbook of Industrial Organization, Vol. 1. North-Holland, Amsterdam, pp. 475-535

[3] Matsumura, T., 1998. A two-stage price-setting duopoly: Bertrand or Stackelberg. Australian Economic Papers 37, 103-118

[4] Ohnishi, K., 2000. A two-stage price-setting equilibrium designed in consideration of goods relevance and strategic relevance. Australian Economic Papers 39, 173-183

[5] Ohnishi, K., 2011. Two-stage quantity-setting games and tacit collusion. Finnish Economic Papers 24, 64-77

[6] Shapiro, C., 1989. Theories of oligopoly behavior. In: Schmalensee, R., Willig, R. D. (Eds.), Handbook of Industrial Organization, Vol. 1. North-Holland, Amsterdam, pp. 329-414

[7] Tirole, J., 1988. The Theory of Industrial Organization. MIT Press, Cambridge 